\title{
How to Decolonize South African Physics
}

\section{South African researchers explain why and how their country's physics should be untethered from its colonial past.}

\author{
By Sarah Wild
}

n 2015, South African universities faced a reckoning. Protestors shut campuses as they called for free higher education and the decolonization of curricula. Academic decolonization involves recognizing and undoing structures and practices inherited from the colonial systems. Physicists heeded these calls and asked for the discipline to be decolonized through actions like changing how physics concepts are taught and increasing the diversity of students and teachers. However, there is still little agreement on what decolonization exactly means. Physics asked a number of physicists what they think a decolonized South African physics would look like.

The interviewed physicists are Azwinndini Muronga, a particle physicist and dean of science at Nelson Mandela University in Port Elizabeth; Justin Jonas, chief technologist at the South African Radio Astronomy Observatory and a physicist at Rhodes University in Makhanda; Tana Joseph, an astronomer and former Royal Society Newton International Fellow at the

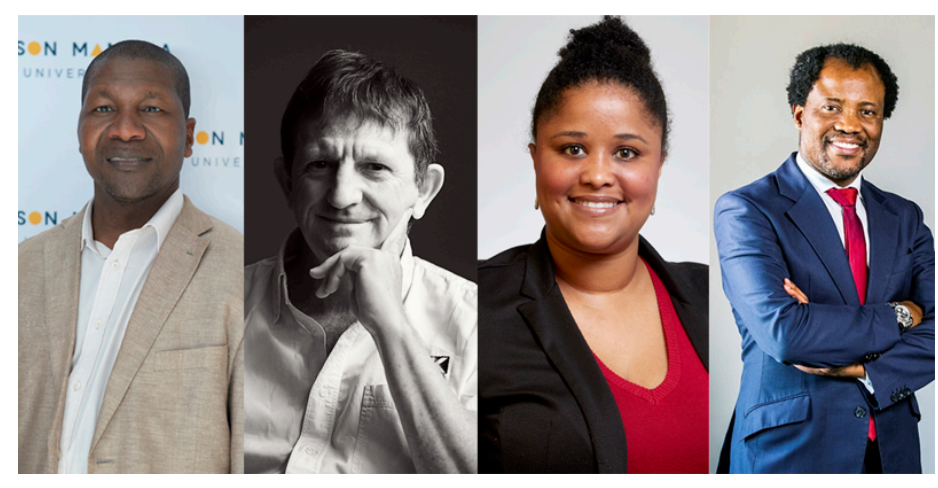

From left to right: Azwinndini Muronga, Justin Jonas, Tana Joseph, and Zeblon Vilakazi.
University of Manchester, UK, and Zeblon Vilakazi, a particle physicist and the incoming vice-chancellor of the University of the Witwatersrand in Johannesburg.

\section{What do you mean by "decolonization" of science?}

"When I talk about decolonization of the physics curriculum, people immediately think we're talking about the content, but it's broader than that," says Azwinndini Muronga. For him, it involves questioning multiple aspects. Who is teaching? Are they representative of the country's diversity or interested in promoting it? Do they shape their teaching based on European models? Do they pick and deliver the content of their classes in a way that is relevant and understandable to South African students? "Once you think about that entire package you will be addressing decolonization," he says.

For Justin Jonas, decolonizing physics also involves showing the relevance of the discipline to a democratic South Africa. He says, "you can't make the assumption that just because you think physics is a good thing, everyone feels the same way. It needs to find its place in the world. It needs to justify itself. I think that physics is a vital part of culture and society," but physicists have the burden of proving to society that they are relevant.

However, Zeblon Vilakazi cautions against the use of the term decolonization. "Decolonization is a political term, and the minute you say decolonization of science, it is political, and we've seen what happens when science gets politicized. It's not good," he says. Instead of using that term, people should talk about inclusion and diversity, which are global challenges, not just South African ones, he says. 


\section{Why do you think South Africa needs to decolonize physics?}

Proponents of decolonization say that without steps to decolonize physics, it will continue to hemorrhage students and lose physicists to developed countries. They are concerned that African students, following attractive fellowships overseas, move into fields that won't get them a job in South Africa, and so they struggle to return. "There is a view that doing your postgraduate studies in South Africa or in the rest of Africa is not a good thing. You need to go and get your degree and definitely do postdoc studies overseas," says Jonas. He says that many people were trained abroad at very good institutions, but they picked their topics based on the fellowship requirements, rather than on what they wanted to do or on what their country thought was a national priority. This issue means that, even though these physicists are well trained and intelligent, they may struggle to find jobs or apply their skills at home, he says.

And South African physics doesn't just lose those physicists. It loses people at every stage of the physics pipeline, says Tana Joseph. "Our system is not set up to prioritize South African or African culture. We have to move away from this 17th-century European idea of what academia is and make it suitable to modern Africa. For example, African women often have children earlier than their European counterparts. In Europe, [child bearing] often affects postdocs. In South Africa, you will see a 22-year-old student with a one-year old. The culture [here] is that everything is built around family."

\section{How would you decolonize physics?}

Azwinndini Muronga wants to see physics concepts taught in a way that is relevant to people in South Africa. He uses the example of Einstein's theory of general relativity, which Einstein explained in a thought experiment using elevators. "You speak of elevators. Students in rural villages don't have elevators. Let's talk about trees, rivers, valleys, climbing the mountains." What's more, South Africa has 11 national languages and only two of them-English and Afrikaans-have a developed lexicon for physics terms. They all should, in order to widen the reach of physics in the country, he says.

Joseph argues that diversity and inclusion should be at the heart of efforts to decolonize physics, which includes taking active steps toward making people who are not White men feel more included. She suggests actions such as correctly pronouncing African names (mispronunciation, she says, is a form of constant microaggression) and having defined and independent reporting structures for racial and sexual harassment. But the burden of these efforts should not fall to women and people of color, as is often the case. "[As a Black woman], I'm expected to do all this outreach, but it acts as a cultural taxation," she says. Institutions and academic departments often ask women and Black people to act as role models and perform outreach to attract more people to the field, but it means "we have to do all this extra stuff while our White men colleagues write papers and get funding," she says.

\section{South Africa wants to transform the demographics of its scientists and students. Is that enough?}

That is part of the "who"-both who gets taught and who does the teaching, says Muronga. "Transformation has to be holistic. You might have an entire White staff component, but if their minds are transformed, within ten years, there will be a change organically. Transformation is not just about numbers; you will not win with a game of numbers. It is about transforming how you do things. In our faculty of science, it must be a diversity of ideas, not just diversity in terms of the demographics. We have to transcend above that."

Sarah Wild is a freelance journalist based in Johannesburg, South Africa. 